\title{
Диахронное изменение параметра ЕРР \\ в русском языке (на основе анализа текста Суздальской летописи по Лаврентьевскому списку)
}

\author{
BEÁTA GYÖRFI \\ Debreceni Egyetem BTK Szlavisztikai Intézet, H-4032 Debrecen, Egyetem tér 1. \\ Institute of Slavic Studies, Faculty of Humanities, University of Debrecen \\ E-mail: blazsenyka@zimbra.unideb.hu
}

(Received: 22 December 2017; accepted: 23 March 2018)

\begin{abstract}
The classification of present-day Russian according to the Extended Projection Principle (EPP) has been a widely discussed issue in the theory of minimalism. The investigation of Old Russian texts suggests that the realization of the EPP requirement differed in Old Russian and has been subject to parametric variation. In the present study, the author tries to shed light on this change by looking at the relative position of S and V, and the ways the EPP is fulfilled in them.
\end{abstract}

Keywords: EPP, diachronic change, Russian, Old Russian, word order changes

\section{Что такое принцип расширенной проекции?}

Принцип ЕРР - подобно большинству принципов генеративной грамматики первоначально был разработан для объяснения поведения подлежащих в английском языке. Согласно этой исходной версии, каждое предложение должно иметь подлежащее - эксплицитно выраженное, пустое или эксплетивное. В зависимости от типологических особенностей языка, подлежащее может располагаться в позициях SpecTP, SpecIP или SpecVP. Вовлечение в исследование большего количества языков способствовало развитию и уточнению взглядов относительно принципа ЕРР.

По позднейшей версии минимализма, согласно т. н. подходу «зонд и цель» (Probe and Goal Approach) (Сномsку 2000), принцип ЕРР регулирует передвижение членов предложения механизмом проверки признаков (согласования). Зондом представляется вершина $\mathrm{T}$, которая имеет неинтерпретируемый признак D (Definiteness - определенность). Она должна найти элемент (цель) с таким же интерпретируемым признаком в своей сфере поиска. Для проверки признаков зонд притягивает к себе цель, т. е. происходит передвижение (копирование) цели в позицию спецификатора зонда. В результате передвижения неинтерпретируемый признак удаляется.

Поскольку удовлетворение ЕРР варьируется по языкам, на основе реализации данного принципа были созданы разные классификации языков (Alexiadou-Anagnastopoulou 1998, Biberauer-Roberts 2005). В нынешней работе я опираюсь на более современное разделение Биберауера и Робертса. 
Для типологизации языков учитывались два расходящихся в отдельных языках параметра: источник признака D и размер категории, содержащей данный признак. Источником признака D в языках «с богатой морфологией» может быть личное окончание глагола, а в языках «с бедной морфологией» DP внутри проекции vP. Что касается размера категории, то он может совпадать или с зондом, или с максимальной категорией, содержащей зонд. Таким образом, языки можно причислять к одному из следующих типов:

1) языки с подъемом вершины (head raising languages), в которых финитный глагол носит признак D, и происходит передвижение V в T. Сюда причисляются канонически т. н. pro-drop-языки с нулевым подлежащим, какими являются греческий и итальянский;

2) языки с spec-подъемом (spec raising languages), в которых признак D находится в составе vP, и они требуют обязательного перемещения DP в позицию SpecТР. Такими языками являются английский и континентальная подгруппа скандинавских языков;

3) языки с эффектом крысолова ${ }^{1}$ на вершине (head pied piping languages), где источником D является глагольная морфология, и имеет место эффект крысолова, т. е. передвижение vP в позицию SpecTP. Таким языком является немецкий;

4) последнюю группу составляют языки, в которых источником неинтерпретируемого признака D является vP, и удовлетворение ЕРP вызывает эффект крысолова, т. е. передвижение DP в позицию Specv. Такими языками являются африкаанс или фарерский.

Изучение ЕРР с позиций русского языка представляется особенно интересным, поскольку причисление современного русского языка к вышеупомянутым группам не является однозначным. Если расширяем исследование данного принципа на предыдущие стадии развития языка, то выясняется, что древнерусский язык имел совершенно другой характер по способам его удовлетворения. В данной статье рассмотрим, как ЕРР действует в современном русском языке, проследим, что выявляется о его действии косвенно из исторических грамматик, и какие результаты дает изучение языка летописи.

\section{Как удовлетворяется ЕРР в современном русском языке?}

Относительно действия ЕРР в русском складывались два предположения. Первое предположение основывается на гипотезе Алексиаду и Анагностопулу (см. AleXiadou-AnAgnastopoulou 1998), согласно которой в некоторых языках ЕРP может удовлетворяться не только передвижением NP в именительном падеже в позицию SресТР, но также передвижением другой группы (XР). Данная гипотеза применялась к русскому языку, и ряд лингвистов (BABYONiSHEV 1996, BAILYN 2011, LAVINE 1998) указывали на то, что в русском

\footnotetext{
1 Эффектом крысолова называется ситуация, когда передвижение группы или вершины влечет за собой включающую ее более крупную составляющую.
} 
языке в позицию SpecTP может перемещаться (1) генитивная NP, (2) дативная NP и (3) PP:

(1) У меня есть деньги.

(2) Маше нравятся дети.

(3) На колене появился синяк.

Согласно другому мнению, представителем которого является Н. А. Слюсарь (см. Slioussar 2011: 2052, МитРенИНА-РОмАновА-СлЮСАРь 2012: 205), в русском ЕРP удовлетворяет только номинативный NP в позиции SpecTP (подобно английскому языку). В доказательство Слюсарь призывает в помощь корпусный анализ языковых данных. При помощи анализа положения наречий образа действия она рассматривает, какую позицию занимает подлежащее. Данные наречия располагаются выше vP, но ниже ТР, т. е. если подлежащее следует за ними, то оно остается в своей исходной позиции внутри vP, a если предшествует им, то оно передвигается в позицию SpecTP.

Примеры (1), (2) и (3) исследовательница объясняет тем, что в данных примерах подлежащее является внутренним аргументом, который не выдвигается в SpecTP, а остается в своей исходной позиции внутри.

Далее, корпусное исследование показывало, что в русском подлежащее довольно часто появляется в абсолютном конце предложения:

(4) Это вьющееся растение хорошо знали древние римляне.

Данное положение Слюсарь объясняет тем, что подлежащее как внешний аргумент и в подобных примерах поднимается в спецификатор ТР, чтобы удовлетворить ЕРР. А потом нижняя составляющая (наречие и глагол) передвигается еще выше, и после этого следует передвижение дополнения. Последние два передвижения обусловлены коммуникативными причинами: первое передвижение вызвано тем, что подлежащее является ремой предложения (содержит выделенную информацию), второе тем, что дополнение является топиком (исходной информацией) (SLIOUSSAR 2011).

В качестве итога можно установить, что в русском языке ЕРР удовлетворяется передвижением номинативного NP в позицию SpecTP. Подлежащие, которые являются внутренними аргументами, не перемещаются в эту позицию, а остаются в своей исходной позиции внутри vP.

Для удовлетворения ЕРР в таких конструкциях некоторые исследователи (PERLMUTTER-MOORE 2002) предлагают ввести нулевые эксплетивы. Надо еще добавить, что наряду с наречными предикатами в русском языке встречаются и полуэксплетивные субъекты (это, mo), хотя они находятся в комплементарной дистрибуции с явными подлежащими. Русский язык допускает и многочисленные изменения порядка слов, которые связаны с актуальным членением. Что касается типологической классификации Биберауера и Робертса, то русский язык на основе перечисленных выше свойств можно отнести к группе языков с spec-подъемом. 


\section{Диахронное изменение способа удовлетворения ЕРР}

Изучение письменных памятников русского языка позволяет нам предположить, что на ранних стадиях своего развития ЕРР действовал иначе, чем в современном русском языке.

Поскольку ЕРР является термином хомскианской теории, он не упоминается в исторических грамматиках, однако косвенно можно выяснить правила его удовлетворения, если рассмотрим вопросы порядка слов и выражения подлежащего. В следующих двух разделах подробно проанализируем эти явления.

\section{Вопрос о порядке слов}

По данным «Всемирного атласа языковых структур» (WALS 2005), современный русский язык - подобно другим славянским языкам - имеет порядок слов SVO. Однако вопрос о порядке слов в древнерусском языке до сих пор не выяснен.

Долгое время полагали, что древнерусский язык характеризовался совершенно свободным порядком слов (БуслАев 1881: 557). Расширяя сферы исследований, ученые обнаружили, что и в древнерусском языке действовал определенный порядок следования элементов, который менялся в зависимости от вида предложения (простое, бессоюзное сложное, сложносочиненное, сложноподчиненное) и от типов связи (с союзом, без союза) (БорковскийКузнЕцов 1963: 359). Некоторые исследователи пришли к выводу, что в древних русских памятниках предложения начинаются с глагола (BERNEKER 1900). Другая группа исторических лингвистов (Борковский 1949: 140, БоркоскийКузнЕцов 1963) настаивает на том, что в грамотах нормой представляется препозиция подлежащего.

В. И. Борковский и П. С. Кузнецов пришли к такому выводу, несмотря на то, что они устанавливают, что число подлежащих с препозицией меньше числа подлежащих с постпозицией (Борковский-Кузнецов 1963: 360). Препозицию сказуемых исследователи возводят к стилистическим причинам: к стремлению автора обратить особое внимание на действие, выраженное сказуемым, или на группу зависящих от сказуемого слов.

Учитывая структурные особенности древних памятников, В. М. Живов устанавливает, что «для восточнославянского нарратива характерен не порядок SV, и не порядок VS, а порядок V. Субъект внутри нарратива обычно эллиптирован. [...] Эллипсис субъекта, как правило, указывает, что субъект тот же, что и в предшествующем предложении (в предшествующей предикативной единице)» (Живов 2008: 7-8). Подлежащее появляется, когда речь заходит о новом агенте повествования.

Современное исследование информационной структуры предложений (МиТРЕНИНА-РОМАНОВА-СЛЮСАРЬ 2012: 209) ПозвоЛяет закЛючИТь, чТо в древ- 
нерусском языке действовал порядок VS. Однако данное предположение не подтверждается анализом исторических данных.

\section{Выражение подлежащего в древнерусском языке}

При изучении древних текстов бросается в глаза, что способы выражения подлежащих отличаются от современной нормы: 1) в древних памятниках обнаруживается меньше явно выраженных подлежащих; 2) в древнерусских текстах мало примеров подлежащих, выраженных личными местоимениями; 3) первые примеры употребления полуэксплетивных местоимений это и то встречаются начиная с среднерусского периода.

Явные подлежащие присутствуют только в контрастивных, эмфатических окружениях, например в фокусе (ЛомтЕв 1956: 35, Борковский 1968: 17 , Борковский 1978: 187).

Что касается местоименных подлежащих, то их малочисленное употребление возводится к морфологическим и прагматическим причинам: в древнерусском языке только личные местоимения 1-го и 2-го лица использовались в эмфатических, контрастивных контекстах. Формы 3-го лица развивались путем реанализа от указательных местоимений. Распространение местоиме-

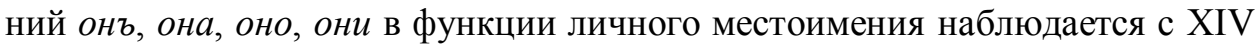
века и прекращается в среднерусском языке.

С точки зрения прагматики, употребляемые местоимения были «сильными», т. е. они несли на себе логическое ударение. Данное свойство проявляется в том, что местоименные подлежащие всегда встречаются в препозиции (Борковский-Кузнецов 1963: 361). Распространение безударных, не эмфатичных явных местоимений 1-го и 2-го лица постулируется к XV веку. Слабые местоимения 3-го лица возникли только в XVI-XVII вв.

В соответствии с терминологией современной типологии, древнерусский язык, в отличие от современного русского языка, был каноническим pro-drop-языком, поскольку он допускал референциальные нулевые подлежащие (pro) во всех контекстах. ${ }^{2}$

\section{Анализ языковых данных}

В этой части исследования проследим, как удовлетворялся ЕРР в древнерусском языке. Данная задача не проста, поскольку большинство письменных памятников данного периода отражают влияние старославянского языка, т. е. проявляют свойства южнославянского языка.

${ }^{2}$ Современный русский причисляется к частичным pro-drop- (partial pro-drop-) языкам, так как он допускает появление нулевых подлежащих в 1-м и в 2-м лице, но вводит ограничения на употребление pro в 3-м лице. Нулевые субъекты почти никогда не обязательны в современном русском языке. В конфигурациях, где нулевой субъект доступен, он всегда может заменяться явным местоимением (MADARIAGA 2018: 178). 
Кроме того, синтаксический анализ древних текстов затрудняется тем, что их нарративная стратегия существенно отличается от современного: древние авторы использовали т. н. «прием цепочечного нанизывания». Они стремились связать в одну цепочку все предикативные единицы, излагающие один эпизод (Борковский 1983: 107, Живов 2008: 6). Полученную нарративную цепочку трудно назвать предложением. Их разделение на предложения часто происходит в ущерб синтаксическим связям.

Корпусом для нынешнего исследования послужил текст Суздальской летописи по Лаврентьевскому списку. Он был написан в XIV веке. Данный период соответствует нашим целям, поскольку в это время происходили существенные изменения видо-временной системы.

Язык Суздальской летописи не однороден: он написан на смешанном языке, в котором переплетаются разговорные (восточнославянские) и книжные (старославянские) элементы. Он содержит авторскую речь летописца, религиозные размышления, прямую речь исторических и светских персонажей. Для достижения большей достоверности я исключила из анализа религиозные (старославянские) компоненты.

Поскольку ЕРР действует на уровне предложений, нарративные цепи я разделила - вслед за А. А. Зализняком - на предикативные единицы, на клаузы (ЗАлизняк 2008: 12). ${ }^{3}$ Следуя определению Я. Г. Тестельца, «клаузой называется любая группа, в том числе и не предикативная, вершиной которой является глагол, а при отсутствии полнозначного глагола - связка или другой элемент, играющий роль связки» (ТЕСТЕЛЕЦ 2001: 256).

Корпус исследования содержит 6506 клауз.

Подавляющее большинство конструкций не содержит явно выраженное подлежащее. Выше уже говорилось о том, что отсутствие подлежащего служит для выражения связи между отдельными цепочками-клаузами, поскольку явно выраженное подлежащее встречается в первом элементе цепочки, а далее только личные окончания глаголов указывают на действующее лицо. Однако, как иллюстрирует следующий пример, не каждое сказуемое цепочки согласовано с подлежащим «кнАзь Гльбъ»:

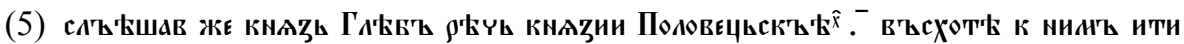

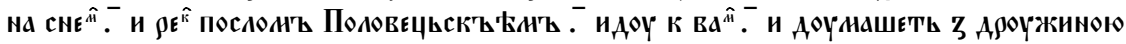

\footnotetext{
${ }^{3}$ Изучая язык новгородских берестяных грамот, А. А. Зализняк расценивает клаузами следующие элементы: 1) простое предложение, выступающее самостоятельно или в составе сложного предложения; 2) т. н. «двухъярусные клаузы», то есть сложные предложения, где придаточное вклинено в состав главного; 3) отдельную клаузу составляет второе или третье сказуемое в ряду однородных сказуемых; 4) отдельную клаузу составляют группы, вершиной которых является нечленное действительное причастие; 5) отдельную клаузу составляют различные эквиваленты придаточных предложений (обороты с нечленными действительными причастиями, дательные самостоятельные конструкции, обороты с обособленным причастием) (ЗАлизняк 2008: 14).
} 


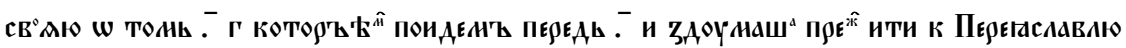
(л. 120 об)

Данный факт подтверждает т. н. pro-drop-характер древнерусского языка. С точки зрения ЕРР представляется интересным, что начальным элементом каждой клаузы является глагол. Данное свойство позволяет нам предположить, что ЕРР в древнерусском языке, подобно современному итальянскому и греческому языку, удовлетворялся за счет передвижения глагола из $\mathrm{V}^{0}$ в позицию $\mathrm{T}^{0}$.

Только 2570 клауз содержит явно выраженное подлежащее. Относительно этих примеров я проследила порядок следования подлежащего и сказуемого.

В 1199 примерах встречаем порядок VS. Данный порядок слов господствует в первом предложении погодных статей:

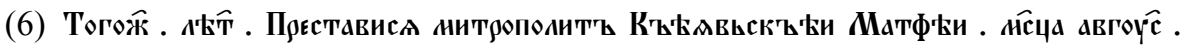

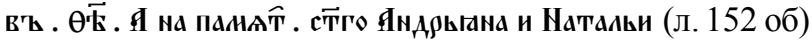

В ряде примеров подлежащее является внутренним аргументом (например при пассивном глаголе):

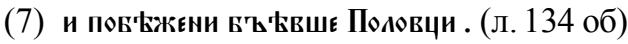

С точки зрения ЕРР особенно показательными представляются конструкции, в которых подлежащее при переходном глаголе остается в своей исходной позиции:

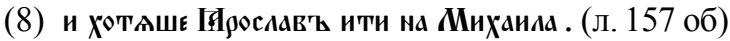

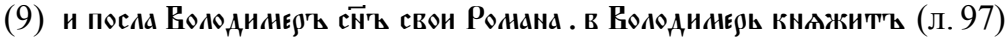

В 1315 клаузах наблюдается препозиция подлежащего. Полагаем, что в данных конструкциях подлежащее выдвинуто на первое место, поскольку оно является прагматически выделенным. Подлежащее в 452 случаях сопровождается энклитикой «же», которая имеет усилительное, противительное значение:

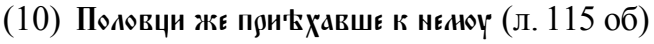

(11) Беренд'ڤАвє Же не даша их'ъ. . (Л. 115 об)

Показательным представляется и количество местоименных подлежащих. Сравнительно широко встречаем анафорические указательные местоимения в функции подлежащего, поскольку они служат для осуществления связности текста:

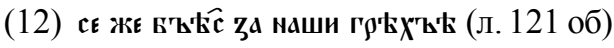


В XIV веке личные местоимения использовались только ограниченно, лишь в таких случаях, где они выступали в фокусе. Данный факт подтверждается и тем, что они часто сопровождаются энклитикой «же»:

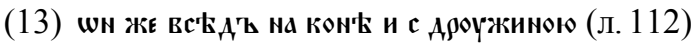

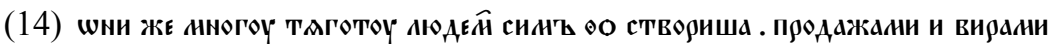
(л. 126 об)

\section{Подведение итогов}

Анализ около 6500 клауз Суздальской летописи указывает на то, что древнерусский по типологической классификации был языком с подъемом вершины. В этом можем убедиться на основе следующих заключений:

1) Удовлетворение ЕРР в древнерусском языке осуществлялось передвижением глагола в начало клауз, в позицию $\mathrm{T}^{0}$.

2) Даже в таких случаях, где встречается явное подлежащее при переходных глаголах, оно не передвигается в позицию SpecTP.

3) Когда встречается явное подлежащее, оно обычно является фокальным (часто сопровождается и энклитикой «же») и предшествует сказуемому. В ряде случаев встречаем и «сильные» личные местоимения в функции подлежащего.

4) Древнерусский язык не содержит фонетически реализованных эксплетивов.

Группа языков с подъемом вершины обладает «богатой морфологией». Древнерусский язык, как известно, имел более широкий круг глагольных форм, чем современный русский язык (настоящее время, префект, имперфект, аорист, плюсквамперфект), и согласование по лицу при помощи связок осуществлялось в прошедшем времени.

\section{Литература}

Alexiadou-Anagnastopoulou 1998 = Alexiadou A., Anagnastopoulou E. Parametrizing AGR. Word order, V-movement and EPP-checking. Natural Language and Linguistic Theory 16 (1998): 491-539.

BAB Yonishev 1996 = BABYonishev M. Structural Conventions in Syntax and Processing. Doctoral Dissertation. Cambridge, Mass., 1996.

BAILYN 2011 = BAILYN J. The Syntax of Russian. Cambridge, 2011.

BERNEKER 1900 = BERNEKER E. Die Wortfolge in den slavischen Sprachen. Berlin, 1900.

BiberaUer-Roberts 2005 = BiBERAUER T., ROBERTS I. Changing EPP parameters in the history of English. Accounting for variation and change. English Language and Linguistics 9 (2005): 5-46.

Chomsky $2000=$ Chomsky N. Minimalist inquiries: the framework. In: Michaels D., Martin R., Uriagereka J. (eds.) Step by Step. Minimalist Essays in Honor of Howard Lasnik. Cambridge, Mass., 2000. 89-155. 
LAVine 1998 = LAvine J. E. Null expletives and the EPP in Slavic. A minimalist analysis. In: BoŠKović Z., Franks S., Snyder W. (eds.) Formal Approaches to Slavic Linguistics 6. Ann Arbor, Mi., 1998. 210-230.

MADARIAGA $2018=$ MADARIAGA N. Diachronic change and the nature of pronominal null subjects: the case of Russian. In: Cognola F., CASAlicchio J. (eds.) Null Subjects in Generative Grammar. A Synchronic and Diachronic Perspective. Oxford, 2018. 171199.

Perlmutter-Moore 2002 = Perlmutter D., Moore J. Language-internal explanation: The distribution of Russian impersonals. Language 78 (2002): 619-650.

SLIOUSSAR $2011=$ SLIOUSSAR N. Russian and the EPP requirement in the Tense domain. Lingua 121 (2011): 2048-2068.

WALS 2005 = HASPELmath M. et al. (ed.) World Atlas of Language Structures. Oxford, 2005.

БоркОвский 1949 = БоРковский В. И. Синтаксис древнерусских грамот. Львов, 1949.

БоРКОВский 1968 = БоРковский В. И. Сравнительно-исторический синтаксис восточнославянских языков. Типы простого предложения. Москва, 1968.

БоРковский 1978 = БоРковский В. И. (ред.) Историческая грамматика русского языка. Москва, 1978.

Борковский 1983 = Борковский В. И. (ред.) Структура предложения в истории восточнославянских языков. Москва, 1983.

БОРКОВСКИЙ-КУзНЕцОв 1963 = БОРКОВСКИй В. И., КУзНЕцОВ П. С. Историческая грамматика русского языка. Москва, 1963.

БУСЛАЕВ 1881 = БУСЛАЕВ Ф. И. Историческая грамматика русского языка. Москва, 1881.

Живов 2008 = Живов В. М. Референтная структура и порядок слов. Дательный самостоятельный в двух древних церковнославянских текстах. Русский язык в научном освещении 2008/1: 5-56.

ЗАлизняк 2008 = ЗАлизняк А. А. Древнерусские энклитики. Москва, 2008.

ЛОмТев 1956 = Ломтев Т. П. Очерки по историческому синтаксису русского языка. Москва, 1956.

МИТРЕНИНА-РОМАНОВА-СЛЮСАРЬ 2012 = МиТРЕНИНА О. В., РОМАНОВА Е. Е., СЛЮСАРЬ Н. А. Введение в генеративную грамматику. Москва, 2012.

ТЕСТЕЛЕЦ 2001 = ТЕСТЕЛЕЦ Я. Г. Введение в общий синтаксис. Москва, 2001. 